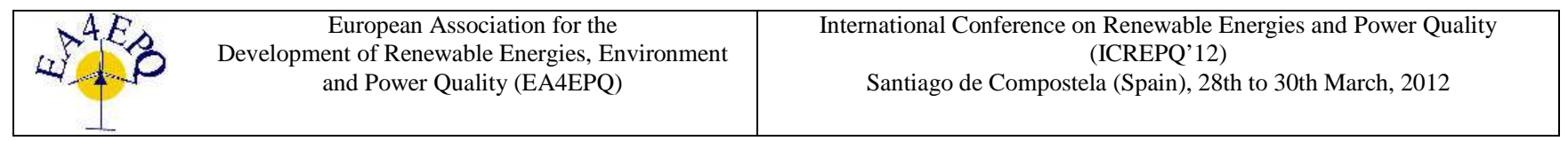

\title{
Design and Construction of Radio-Controlled Glider with Renewable Energy Capabilities
}

\author{
M. Tubul , S. Stamker and E. Fisher \\ Department of Mechanical Engineering \\ Shamoon College of Engineering (SCE), \\ Beer-Sheva, Israel \\ e-mail: etanfi@sce.ac.il
}

\begin{abstract}
Thermal columns are a meteorological phenomenon which is frequently used by birds to rise without requiring wing power. Imitating this behaviour with an aircraft can utilize this lift to provide energy for the electrical components of the system.
\end{abstract}

In this study, a radio-controlled glider with a built-in wind turbine and generator was designed and constructed. The generator is intended to provide renewable energy during glides, especially when thermal columns are harnessed.

The glider was constructed using composite materials, which combine a high level of strength together with light-weight, improving energy efficiency. Turbine design was implemented using a duct-fan model which increases air flow to the generator.

Test flight measurements indicate efficient battery recharging can be obtained during glides. The system may be implemented in manned or unmanned gliders, for agricultural, civil, or security uses, such as unmanned surveillance airplanes.

\section{Key words}

\section{Glider, UAV, wind turbine, battery charger, thermal column.}

\section{Introduction}

This work focuses on utilizing wind energy for regenerating power in aircrafts. Wind power is readily available and free to use, as well as being a non-polluting source of energy [1]. Over the last decades, wind power is becoming increasingly used and studied as an energy source. These developments have also contributed to improving efficiency and output power [2-5].

In electric gliders, the motor is used to reach desired altitude or location for gliding. After the motor switches off, the glider can glide freely for a certain period of time.
The glide time depends on internal and external conditions. The internal conditions depend on structure design parameters, including size, weight, and wing-span [6]. External conditions include weather, wind speed and thermal columns, as well as pilot proficiency [7].

Thermal columns are a natural phenomenon in which temperature differences create upward wind turbulence [7]. In order to harness the thermal energy, the glider can be flown around the thermal column. The thermal lift decreases with altitude. The technique for gliding involves encircling the thermal column to gain altitude. After gaining altitude, the glider can glide towards another thermal column. Using this technique, great distances may be covered. Alternatively, this technique can be used to generate power using a wind turbinegenerator.

In this study, a radio-controlled glider was designed and developed with an in-built wind generator. The glider incorporates a wind turbine to generate electricity which may be used to power the glider components or recharge its batteries. The platform was designed to utilize meteorological conditions, such as thermal columns, to achieve maximal efficiency.

The turbine is designed to be operated while gliding. For example, the glider can rise by catching a thermal column, which provides natural lift. During the rise, and the following descent, the engine is not required. Theoretically, this cycle can go on indefinitely, providing as much energy as required to recharge the system.

Design considerations include three main categories: structural design, design of the wind turbine generator system, and design of an efficient circuit for energizing and recharging the relevant systems. This paper focuses on structural design and provides initial test results for the turbine and generator. 


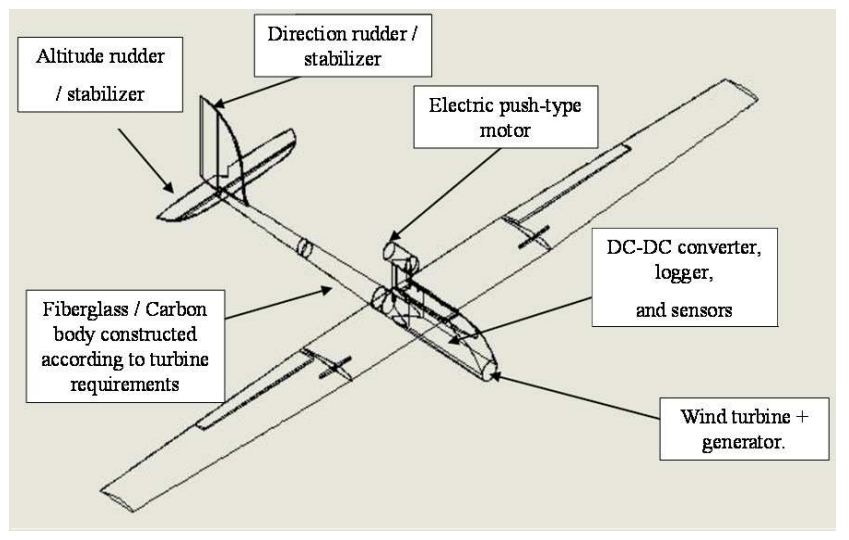

Fig. 1. Glider design - top propeller for lift-off and boost, front propeller for wind turbine. Main body components.

\section{Design and Construction}

Design considerations include three main categories. The first is structural design [6]. The structural considerations include materials and aerodynamics. The second category is structural, mechanical and electrical design of a wind turbine generator system [1]. The third category is the design of an efficient circuit for energizing and recharging the relevant systems [2].

The glider was designed to achieve maximal performance when gliding through a thermal column. The glider was designed with two propellers. The driving propeller is located above the plane body. This propeller provides initial lift and provides the extra power required to keep the glider in the air. The wind turbine is located in the front of the glider (Fig. 1).

The two main forces operating on the glider wing are lift (L) and drag (D) [6]. Lift and drag, respectively, express the forces perpendicular and parallel to the air flow along the wing. The ratio between drag and lift also indicates the distance (in meters) that can be glided through given an altitude drop of 1 meter. The main design parameter affecting drag is the aspect ratio (AR), defined as:

$$
A R=\frac{b^{2}}{S},
$$

where $b$ is the wing span and $S$ is the wing area. A higher aspect ratio decreases the influence of drag induced by air flow. Strength and weight calculations lead to design of the glider with an AR of 20. Further specifications of the glider appear in table I.

Table I. - Main design parameters

\begin{tabular}{|l|l|}
\hline \multicolumn{1}{|c|}{ Parameter } & \multicolumn{1}{c|}{ Value } \\
\hline Body Length & $1700 \mathrm{~mm}$ \\
\hline Wing span & $3400 \mathrm{~mm}$ \\
\hline Weight & $3800 \mathrm{gr}$ \\
\hline Materials (body) & $\begin{array}{l}\text { Kevlar, Microglass, } \\
\text { Fiberglass }\end{array}$ \\
\hline Materials (wings) & Balsa core, Fiberglass \\
\hline Engine & $550-800 \mathrm{~W}$ \\
\hline Battery & 3 cell, 3000 mA, 11.1 V \\
\hline
\end{tabular}

The glider was constructed using composite materials. The main advantages of composite materials are: low weight, high strength and rigidity, and a high tolerance to corrosion. The fibrous nature of composite materials also provides a high degree of fracture toughness. A combination of several fibers such as Kevlar, microglass, and fiber-glass, was used.

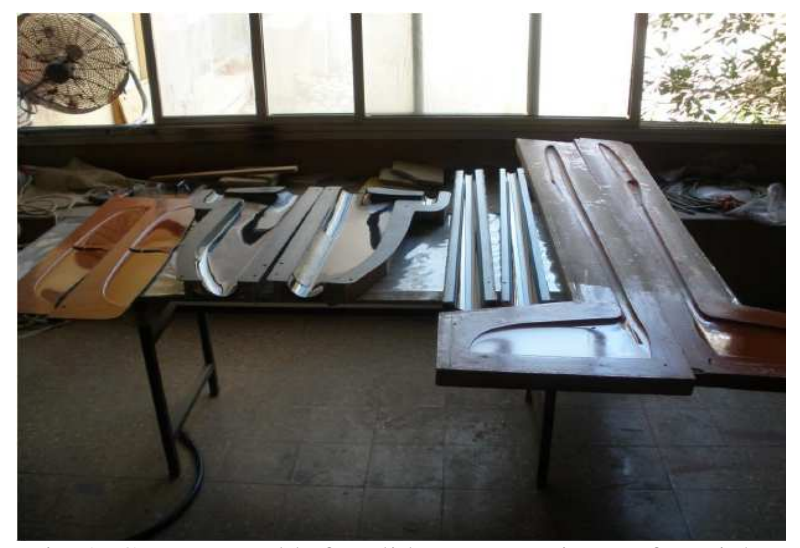

Fig. 2. Custom moulds for glider construction. Left to right: Vertical stabilizer, main body, tail-piece, horizontal stabilizer.

The process of preparing the body and wings involved creating custom-made moulds. The fibers and resin contributed to the light weight of the glider. Fig. 2 shows the custom-built moulds for the body, stabilizers (see Fig. 1.) and tail-piece. Fig.3. shows the main-body mould and the composite materials - Kevlar fabric and micro-glass. The Kevlar is placed in the mould and doused in epoxy resin. The mould is set in a vacuum and heated for several hours. The finished product is coated with fine micro-glass.

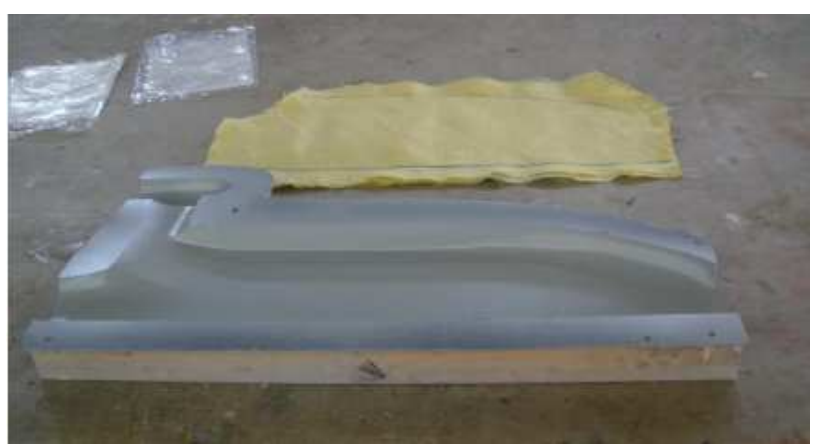

Fig. 3. Mould with Kevlar fabric (top-center) and micro-glass (top-left)

\section{Turbine / Generator System}

The power of a wind turbine can be calculated using [1]:

$$
P=\frac{\pi}{8} \rho D^{2} v^{3},
$$

where $\rho$ is the air density, $D$ is the turbine diameter, and $v$ is the wind velocity. The diameter of the turbine in the glider is $7 \mathrm{~cm}$. According to Betz' law, the actual power is lower by a factor of 0.593 . 
In order to minimize the losses of conventional propellers, a duct-fan design was chosen. This limits the propeller dimensions, but reduces blade tip losses and is more efficient at providing thrust at low speed. Fig. 4 shows the turbine duct. The equally-placed notches direct the airflow towards the fan, creating a vortex, and increasing the output air speed. A lab test yielded a $12.5 \%$ increase in wind speed at $80 \mathrm{~km} / \mathrm{h}$.

In the test flight described below, a standard, 5 blade fan, normally used in computers, was used. This 'electric recycling' approach provides insight for further turbine design [3].

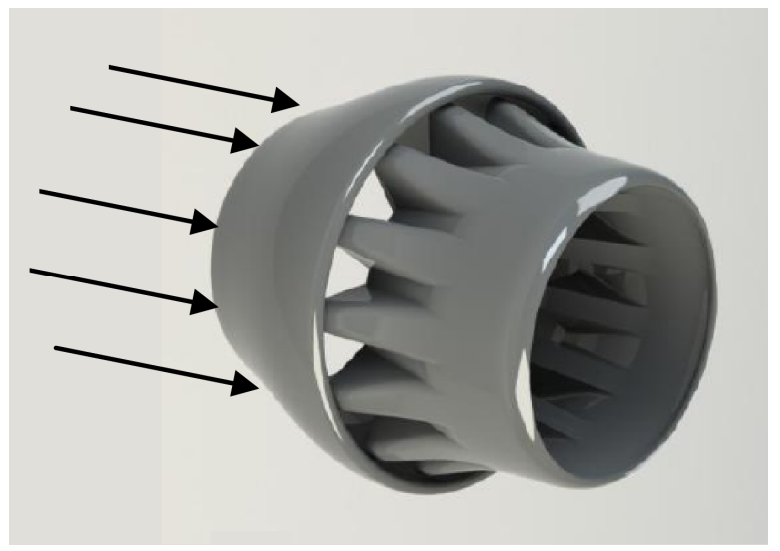

Fig. 4. Air-duct for wind turbine.

A 24 volt DC generator was chosen for recharging the 3cell, $3000 \mathrm{maH}, 11.1$ volt, lithium-ion battery-pack. Recharging was tested under lab conditions successfully.

\section{Test Flights}

Two test flights were performed. The first flight was performed after construction. This flight was performed without the turbine. Fig. 5 shows the glider after landing.

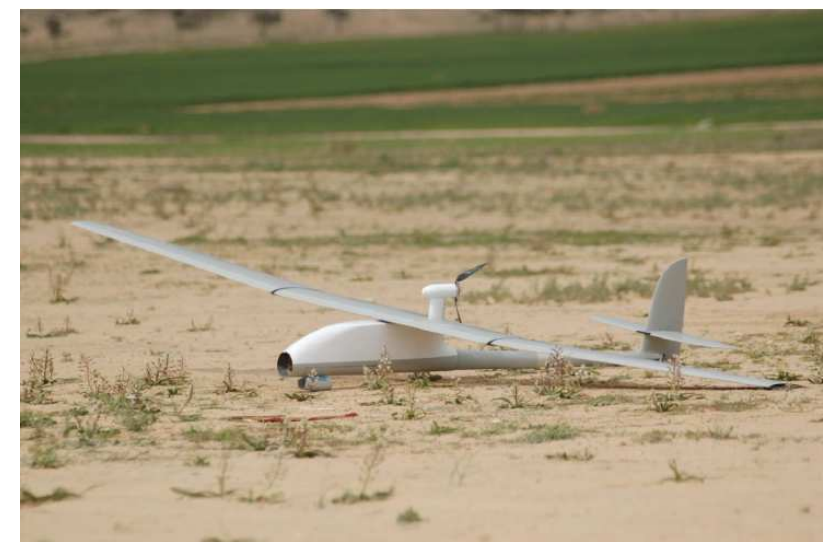

Fig. 5. The first test flight - safe landing. This flight was performed without the turbine.

The second test flight was performed with a complete flight recording system (logger). A standard computer-fan propeller was installed in the glider nose and was connected to the logger using a tachometer. The test flight was performed to examine performance in terms of velocity, engine use, and renewable energy potential. The test flight was performed on a warm day $\left(27^{\circ} \mathrm{C}\right)$ with an average wind speed of $1 \mathrm{~m} / \mathrm{sec}$. The logger measured the following electro-mechanical parameters: Altitude, glider speed, turbine angular velocity (RPM), power consumption, current consumption and voltage.

Fig. 6. shows the original logger output for the glider altitude, speed (both measured using GPS), and the angular velocity of the propeller.

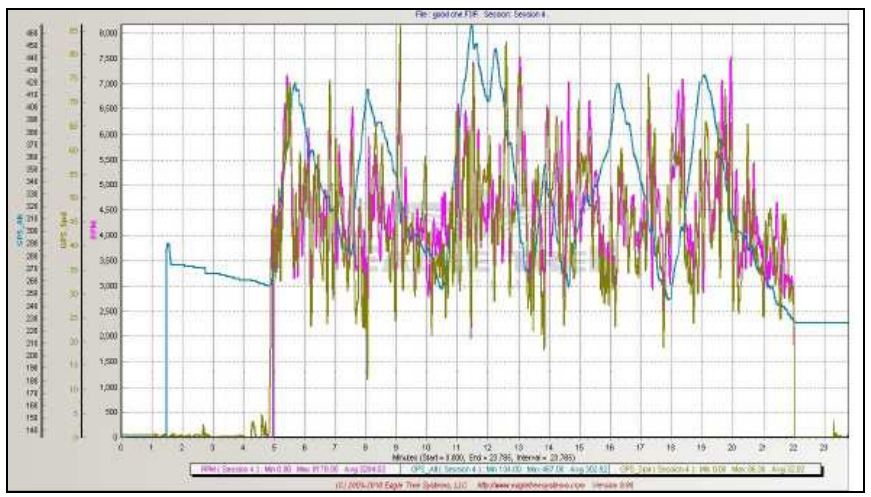

Fig. 6. Logger recording of altitude, speed, and angular velocity.

Fig. 7 shows the glider power consumption for the first 6 minutes of the test flight. With the take-off beginning at approx. $t=30 \mathrm{sec}$, there motor was used for 2.25 minutes and was off for 3.25 minutes, indicating the glide time to be approximately $60 \%$ of the flight time.

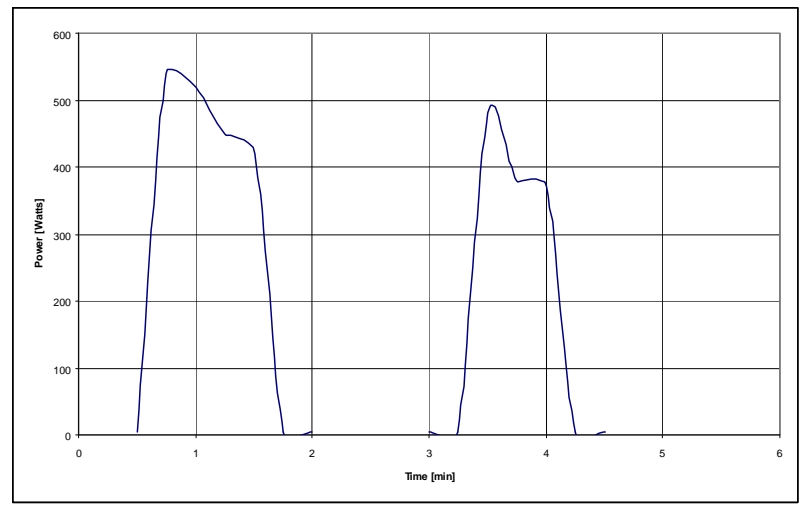

Fig. 7. Glider power consumption during test flight.

Fig. 8 shows an interpolated curve of the glider altitude during the first 6 minutes of flight. After initial take-off, gliding begins. Over approximately 2 minutes, the altitude decreases by 100 meters. A second boost from the engine increases the altitude, and a second glide begins.

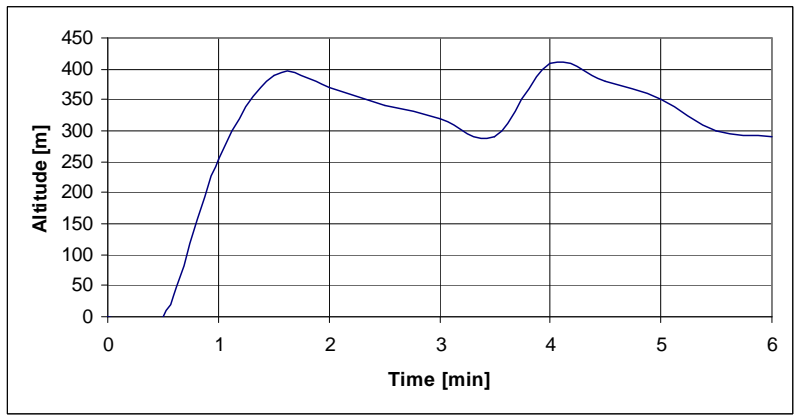

Fig. 8. Glider altitude. 
Fig. 9 shows the glider speed, recorded by GPS. The average wind speed, being $1 \mathrm{~m} / \mathrm{sec}$, is negligible. Comparing altitude and velocity during the glides between 2-3 minutes, and between minutes $4-5$, shows a rise in velocity as the glider loses altitude. This indicates the turbine ability to generate power during glides.

Fig. 10 shows the angular velocity of the generator shaft. As may be expected, the behavior of the angular velocity closely follows that of the glider speed.

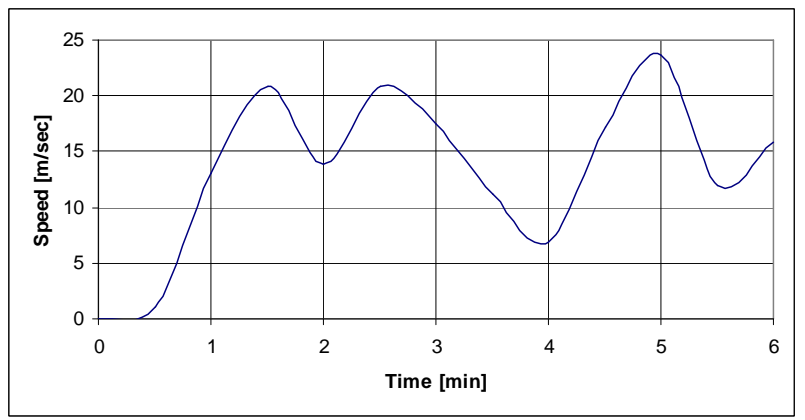

Fig. 9. Glider speed.

The tip-speed-ratio (TSR) can be calculated from the speed and angular velocity. TSR is defined as [5]:

$$
\lambda=\frac{V_{c}}{V_{r}},
$$

where $V_{r}$ is the glider speed, and $V_{c}$ is the circumferential speed:

$$
V_{c}=\frac{\pi n r}{30},
$$

$n$ is the turbine rotations per minute, and $r$ is the blade length. The resulting speed ratio is between 1 and 2 , with an average of 1.3. This TSR range is considered low [5]. However, it is expected to improve after further development of the turbine.

Table II shows the power expected to be gained and the time that would be required to recharge the batteries. The average glider speed in this test flight was $15.7 \mathrm{~m} / \mathrm{sec}$. In order to recharge an 11.1 volt battery at the average speed, it would take approximately 2 hours to recharge 1000 $\mathrm{maH}$, or 6 hours to fully recharge the glider batteries (3000 $\mathrm{maH})$.

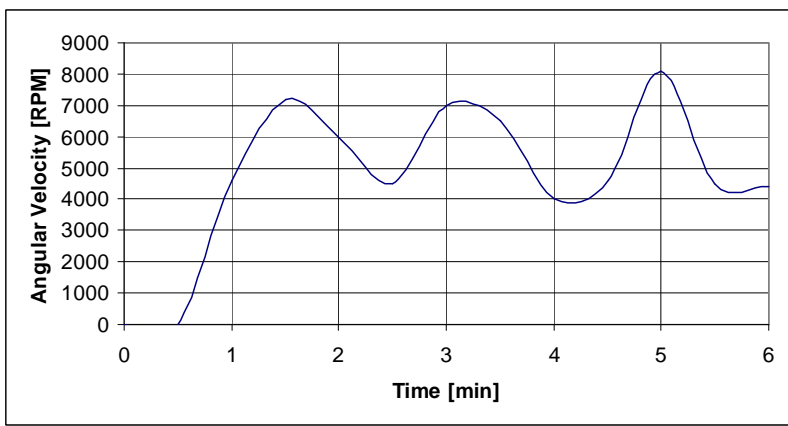

Fig. 10. Angular velocity of generator shaft.
Table II. - Renewable energy statistics

\begin{tabular}{|l|c|c|c|c|}
\hline \multirow{2}{*}{ Parameter } & \multicolumn{4}{|c|}{ Glider velocity [m/sec] } \\
\cline { 2 - 5 } & $12(\mathrm{~min})$ & 15 & $\mathbf{1 5 . 7}$ & $20(\mathrm{max})$ \\
\hline Power (Watt) & 2.37 & 4.63 & $\mathbf{5 . 3 1}$ & 10.99 \\
\hline Voltage (V) & 11.1 & 11.1 & $\mathbf{1 1 . 1}$ & 11.1 \\
\hline Current (mA) & 214 & 420 & $\mathbf{4 8 0}$ & 990 \\
\hline $\begin{array}{l}\text { Charge Time } \\
\text { (1000 mAH) }\end{array}$ & 4.68 & 2.40 & $\mathbf{2 . 0 9}$ & 1.01 \\
\hline $\begin{array}{c}\text { Charge Time } \\
(3000 \mathrm{mAH})\end{array}$ & 14.03 & 7.19 & $\mathbf{6 . 2 7}$ & 3.03 \\
\hline
\end{tabular}

\section{Conclusion}

This paper described the design and construction of a radio-controlled glider with renewable energy capabilities. The paper focused on the physical construction of the glider. Feasibility for recharging the system batteries was shown. Real flight experiments indicated renewable energy is immediately available.

Future work is planned to include further design of the wind turbine as well as full implementation of a generator charger circuit. Finally, in order to gain significant energy, glider operation will be directed towards flying in thermal columns.

\section{References}

[1] W. Shepherd and L. Zhang, Electricity generation using wind power, World Scientific Publishing, 2010.

[2] M. Predescu, A. Bejinariu, A. Nedelcu, O. Mitroi, C. Nae, M. V. Pricop, and A. Craciunescu, "Wind tunnel assessment of small direct drive wind turbines with permanent magnets synchronous generators," in Proceedings of the International Conference on Renewable Energies and Power Quality (ICREPQ'08), 2008.

[3] A. Gálvez, M. Lejárraga, J. S. Artal, A. Usón, and F. J. Arcega, "Recycling of small electrical machines and its applications for low cost wind turbines," in Proceedings of the International Conference on Renewable Energies and Power Quality (ICREPQ'03), 2003.

[4] C. Ghita, D.I. Ceaconu, A. I. Chirila, V. Navapescu, and D. Ilina, "Lab model for a low power wind turbine system," in Proceedings of the International Conference on Renewable Energies and Power Quality (ICREPQ'09), 2009.

[5] N.S. Çetin, M.A. Yurdusev, R. Ata., and A. Özdemir, "Assessment of Optimum Tip Speed Ratio of Wind Turbines," Mathematical and Computational Applications, Vol. 10, No. 1, pp 147-154, 2005.

[6] E. E. Sechler and L. G. Dunn, Airplane structural analysis and design, Chapman and Hall, 1963.

[7] W. Angevine, "Thermal structure and behaviour," 2006. http://www.rcsoaring.com/docs/thermals_2006.pdf 